\title{
Novel Proteins Regulated by mTOR in Subependymal Giant Cell Astrocytomas of Patients with Tuberous Sclerosis Complex and New Therapeutic Implications
}

\author{
Magdalena Ewa Tyburczy, ${ }^{*}$ Katarzyna Kotulska, ${ }^{\dagger}$ \\ Piotr Pokarowski, ${ }^{\ddagger}$ Jakub Mieczkowski, ${ }^{*}$ \\ Joanna Kucharska, ${ }^{*}$ Wieslawa Grajkowska, ${ }^{\dagger}$ \\ Maciej Roszkowski, ${ }^{\S}$ Sergiusz Jozwiak, ${ }^{\dagger}$ \\ and Bozena Kaminska* \\ From the Laboratory of Transcription Regulation, * the Nencki \\ Institute of Experimental Biology, Warsaw; the Departments of \\ Neurology and Epileptology, ${ }^{\dagger}$ and Neurosurgery, ${ }^{\S}$ the Children's \\ Memorial Health Institute, Warsaw; and the Faculty of \\ Mathematics, Informatics, and Mechanics, ${ }^{\ddagger}$ University of \\ Warsaw, Poland
}

Subependymal giant cell astrocytomas (SEGAs) are rare brain tumors associated with tuberous sclerosis complex (TSC), a disease caused by mutations in TSC1 or TSC2, resulting in enhancement of mammalian target of rapamycin (mTOR) activity, dysregulation of cell growth, and tumorigenesis. Signaling via mTOR plays a role in multifaceted genomic responses, but its effectors in the brain are largely unknown. Therefore, gene expression profiling on four SEGAs was performed with Affymetrix Human Genome arrays. Of the genes differentially expressed in TSC, 11 were validated by real-time PCR on independent tumor samples and 3 SEGA-derived cultures. Expression of several proteins was confirmed by immunohistochemistry. The differentially-regulated proteins were mainly involved in tumorigenesis and nervous system development. ANXA1, GPNMB, LTF, RND3, S100A11, SFRP4, and NPTX1 genes were likely to be mTOR effector genes in SEGA, as their expression was modulated by an mTOR inhibitor, rapamycin, in SEGA-derived cells. Inhibition of mTOR signaling affected size of cultured SEGA cells but had no influence on their proliferation, morphology, or migration, whereas inhibition of both mTOR and extracellular signal-regulated kinase signaling pathways led to significant alterations of these processes. For the first time, we identified genes related to the occurrence of SEGA and regulated by mTOR and demonstrated an effective modulation of SEGA growth by pharmacological inhibition of both mTOR and extracellular signal-regulated kinase signaling pathways, which could represent a novel therapeutic approach. (Am J Pathol 2010, 176:1878-1890; DOI: 10.2353/ajpath.2010.090950)

Subependymal giant cell astrocytomas (SEGAs) are rare, low-grade brain tumors (World Health Organization Grade I) of a mixed glioneuronal lineage. ${ }^{1,2}$ They are observed in $10 \%$ to $20 \%$ of patients with tuberous sclerosis complex (TSC) and are the major cause of morbidity in children and young adults with TSC. ${ }^{3}$ The disease affects about one in 6000 people, is characterized by the formation of benign tumors in multiple organs (mainly brain, heart, kidneys, skin, or lungs), and is often associated with epilepsy, mental retardation, and autism. ${ }^{4,5}$ Tuberous sclerosis complex is caused by mutation in one of two tumor suppressor genes, TSC1 and TSC2, which encode Hamartin and Tuberin, respectively. ${ }^{6,7}$ Both proteins form the TSC complex that inhibits the mammalian target of rapamycin complex 1 (mTORC1). Within the TSC complex, TSC1 stabilizes TSC2, whereas TSC2 acts as a GTPase-activating protein for the small GTPase RHEB (Ras homolog enriched in brain). ${ }^{8-10}$ Mutation in one of the genes leads to elevated RHEB-GTP levels and activation of mTORC1, which further triggers a downstream kinase signaling cascade, including phosphorylation of eukaryotic translation initiation factor $4 \mathrm{E}$-binding proteins and p70 S6 kinases, proteins involved in translation initiation and ribosome biogenesis. ${ }^{11}$ Increased

Supported by Ministry of Science and Higher Education grant 3/0-PBZMNil-2/1/2005 (to B.K.) and PB-916/P01/2006/31 (to S.J.). M.E.T. is a student of the Postgraduate School of Molecular Medicine.

Accepted for publication December 15, 2009.

Address reprint requests to Prof. Bozena Kaminska, Laboratory of Transcription Regulation, The Nencki Institute of Experimental Biology, 3 Pasteur Street, 02-093 Warsaw, Poland. E-mail: bozenakk@nencki. gov.pl. 
activation of mTOR kinase results in disorganized cellular overgrowth, abnormal differentiation, and formation of neoplasms. ${ }^{12,13}$

Clinical trials with rapamycin (sirolimus), a specific inhibitor of mTORC1, have been initiated and showed a regression of SEGAs after a systemic administration of the drug. ${ }^{14,15}$ However, molecular mechanisms underlying a regression of SEGAs in TSC patients are still poorly understood. By combining the use of rapamycin, transcriptional profiling, and RNA interference, more than 400 genes in yeast and 90 genes in $D$. melanogaster were identified to be up- or down-regulated by mTOR inhibition. ${ }^{16-19}$ Moreover, the gene expression analysis in Tsc2 null murine neuroepithelial progenitor cells revealed altered expression of many genes encoding proteins involved in cell growth, adhesion, and neuronal transmission. ${ }^{20}$ However, understanding of mTOR signaling and its downstream targets in the human brain remains far from complete.

In the current study, gene expression profiling on SEGA samples was performed and we identified specific genes involved in tumorigenesis (up-regulated) and the nervous system development (down-regulated) in SEGAs or SEGA-derived cell cultures when compared with the normal brain or cultured human astrocytes. Immunohistochemistry on paraffin-embedded sections confirmed up-regulated levels of several identified proteins in SEGAs. Rapamycin affected the expression of selected genes in SEGA-derived cell cultures showing their dependence on mTOR signaling. Moreover, pharmacological inhibition of mTOR and extracellular signal-regulated kinase (ERK) signaling pathways in cultured SEGA cells affected their proliferation, size, morphology, and migration. Specific expression of the identified genes in the pathological brain and the influence of MTOR and ERK signaling on biology of SEGA cells may provide explanation of how these pathways contribute to the pathogenesis of SEGA and neurological alterations associated with tuberous sclerosis complex.

\section{Materials and Methods}

\section{Patient Samples}

Ten SEGA samples and three control brain tissues were accessed from the Department of Pathology and Department of Pediatric Neurology, The Children's Memorial Health Institute, Warsaw, Poland. SEGA specimens were originally obtained from tumors immediately after resection from TSC patients diagnosed clinically according to the criteria of Roach. A genetic analysis proved that four of five analyzed patients had mutations in TSC2. Control tissues consisted of periventricular regions of non-TSC patients. Two additional controls were: FirstChoice $\AA \mathrm{Hu}-$ man Brain Reference RNA pooled from 23 donors (Applied Biosystems, Darmstadt, Germany) and Human Brain Total RNA pooled from 2 donors (Clontech, SaintGermain-en-Laye, France).

\section{RNA Isolation, Affymetrix GeneChip Microarray, and Data Analysis}

Total RNA was prepared by Tri-Reagent (Sigma-Aldrich, Munich, Germany) extraction from snap-frozen tissues. RNA was cleaned up using RNeasy Mini Kit (Qiagen, Hilden, Germany) which was also used to isolate total RNA from harvested cells. The quality and quantity of total RNA were verified using the Agilent bioanalyzer (Agilent Technologies, Santa Clara, CA). Total RNA (5 $\mu \mathrm{g})$ was converted to double-stranded cDNA. Biotinlabeled cRNA was generated after an in vitro transcription reaction. The cRNA was fragmented and then hybridized to a control microarray (Test3) and then, after sample quality evaluation, to the arrays HG-U133 Plus 2.0 (Affymetrix, Santa Clara, CA). Immediately after hybridization, the arrays underwent automated washing and staining steps. Finally, they were scanned and the software computed intensities for each cell. Samples hybridization was done in the Department of Nuclear Medicine and Endocrine Oncology, Maria Sklodowska-Curie Memorial Cancer Center and Institute of Oncology, Gliwice, Poland, using a standard protocol provided by Affymetrix. Microarray data were analyzed using five popular preprocessing methods: RMA, ${ }^{21}$ MAS5.0 (Affymetrix Inc. 2002,), GC-RMA, ${ }^{22}$ MBEl pmonly, ${ }^{23}$ and PDNN. ${ }^{24}$ This was done to identify changes in gene expression robust to a particular choice of a preprocessing method. Probe set measurements were transformed into measurements for genes using annotation provided in the Ensembl database. SEGA gene expression profiling data were deposited at ArrayExpress, accession: E-MEXP-2351. Additionally, to remove a possible cross-hybridization effect, all probe sets with annotation to more than one gene were excluded from further analysis. Furthermore, expression measurements computed for probe sets annotated explicitly to the same gene were averaged using robust Tukey biweight function. Changes in gene expression were examined separately for each preprocessing algorithm using Welsh $t$ test. Next, to obtain a robust estimator of $P$ values, five values of $t$ test computed for each gene were averaged with Tukey biweight function, and the mean values were used to obtain $P$ values. Finally, we computed q values for all analyzed genes. That allowed us to select a set of differentially expressed genes in which false discovery rate was at $5 \%$ level. Most of preprocessing and all statistical computations were done with the R programming environment and Bioconductor packages. ${ }^{25}$ Only the PDNN expression measure was computed with the original PerfectMatch software. ${ }^{24}$

\section{Reverse Transcription and Real-Time PCR Analysis}

Total RNA (1 $\mu \mathrm{g})$ was used to synthesize cDNA by extension of oligo(dT) ${ }_{15}$ primers $(2.5 \mathrm{mmol} / \mathrm{L})$ with 200 units of M-MLV reverse transcriptase (Sigma-Aldrich, Munich, Germany). Real-time PCR amplifications were performed in duplicate on cDNA equivalent to 25 ng RNA in 20- $\mu$ l reaction volume containing 1xSYBR GREEN PCR Master Mix 
(Part. No. 4309155, Applied Biosystems, Darmstadt, Germany) and the primer sets QuantiTect Primer Assays (200; Qiagen, Hilden, Germany): Hs_ANXA1_1_SG, Hs_CNDP1_ 1_SG, Hs_GPNMB_1_SG, Hs_KIAA1189_1_SG, Hs_LTF_ 2_SG, Hs_MBP_1_SG, Hs_NEUROD1_1_SG, Hs_NPTX1_ 1_SG, Hs_RND3_1_SG, Hs_S100A11_1_SG, and Hs_SFRP4_2_SG. 18SrRNA was used as an internal standard reference. 18SrRNA primers were designed with the Primer Express Software (Applied Biosystems, Foster City, CA): forward 5'-CGGACATCTAAGGGCATCAC-3' and reverse 5'-AACGAACGAGACTCTGGCAT-3'. The thermal cycling conditions were as follows: $50^{\circ} \mathrm{C}$ for 2 minutes, $95^{\circ} \mathrm{C}$ for 10 minutes, followed by 40 cycles of 15 seconds at $95^{\circ} \mathrm{C}$ for denaturation, and 1 minute at $60^{\circ} \mathrm{C}$ for annealing and extension. The relative quantification of gene expression was determined with ABI PRISM 7700 Sequence Detection System using the comparative CT method.

\section{Immunohistochemistry}

Immunostaining was performed on 5- $\mu$ m sections of paraffin-embedded brain tissues of five SEGAs and five control brains obtained from the Department of Pathology, The Children's Memorial Health Institute, Warsaw, Poland. The sections were deparaffinized in xylene, hydrated with a descending ethanol series, and rinsed with deionized water. For each washing $0.05 \mathrm{~mol} / \mathrm{L}$ Tris-buffered saline, pH 7.4 was used. To retrieve the antigen, sections were boiled for 10 minutes in citrate buffer, $\mathrm{pH}$ 6.0. Endogenous peroxidase activity was blocked for 30 minutes with $0.3 \%$ hydrogen peroxide. Sections were then incubated overnight at $4^{\circ} \mathrm{C}$ with the following antibodies: anti-human-Annexin A1 (Abcam, Cambridge, UK, diluted 1:300), anti-human-GPNMB (Abcam, Cambridge, UK, diluted 1:300), and anti-human-S100A11 (ProteinTech Group, Manchester, UK, diluted 1:50) in 1\% Swine Serum (Dako, Hamburg, Germany) in Tris buffered saline. Sections were incubated sequentially with biotinylated secondary anti-rabbit or anti-mouse antibodies and extravidin- or streptavidin-peroxidase conjugate (Sigma-Aldrich, Munich, Germany). Peroxidase activity was revealed by 3,3'-diaminobenzidine ( $\mathrm{DAB}, 10$ minutes), and then counterstaining was performed with hematoxylin (Sigma-Aldrich, Munich, Germany). Finally, sections were dehydrated through ethanols, cleared in xylene, and mounted. Sections without primary antibodies were used as negative controls.

\section{Cell Culture and Treatment}

Freshly resected SEGA samples from three patients were collected, cut into small fragments, and trypsinized for 20 minutes in $37^{\circ} \mathrm{C}$. Afterward, cell suspension was centrifuged and suspended in Dulbecco Modified Eagle's Medium (DMEM) supplemented with $10 \%$ fetal bovine serum (FBS; Gibco Invitrogen, Karlsruhe, Germany) and antibiotics ( $50 \mathrm{U} / \mathrm{ml}$ penicillin, $50 \mu \mathrm{g} / \mathrm{ml}$ streptomycin; SigmaAldrich, Munich, Germany). Cells were maintained for about 2 weeks before they were used in experiments. Normal Human Astrocytes (Clonetics ${ }^{\circledR} \mathrm{NHA}$ ) were cultured in Astrocyte Medium (Lonza, Walkersville, MD).
SEGA and NHA were treated with rapamycin (LC Laboratories, Woburn, MA), U0126 (Cell Signaling Technology, Danvers, MA), or dimethyl sulfoxide (DMSO; SigmaAldrich, Munich, Germany), a solvent for both drugs. During the treatment cells were grown in DMEM with $2 \%$ FBS.

\section{Western Blot Analysis}

Whole-cell protein extracts from SEGA and NHA cells were prepared as described, ${ }^{26}$ loaded onto $10 \%$ polyacrylamide gel, electrophorezed, and transferred to a nitrocellulose membrane (Amersham Pharmacia Biotech, Piscataway, $\mathrm{NJ}$ ). Membranes were incubated overnight at $4^{\circ} \mathrm{C}$ with primary antibodies: anti-phospho-p70 S6 Kinase (T389), anti-p70 S6 Kinase (clone 49D7), anti-phospho-ERK1/2 (T202/Y204), and anti-ERK1/2 (1:1000, Cell Signaling Technology, Danvers, MA). After blocking in $5 \%$ low-fat milk in TBS-T (0.1\% Tween 20/Tris-buffered saline, $\mathrm{pH}$ 7.6), the membranes were incubated overnight with primary antibodies diluted in a blocking buffer and then, for one hour, with a secondary anti-rabbit antibody linked to horseradish peroxidase (1:2000, Cell Signaling Technology, Danvers, MA). Membranes were reprobed with a monoclonal anti- $\beta$-Actin-Peroxidase conjugated antibody (1:50000, Sigma-Aldrich, Munich, Germany) that served as a loading control. Immunocomplexes were visualized by the enhanced chemiluminescence system (Amersham Pharmacia Biotech, Piscataway, NJ).

\section{MTT Metabolism Test}

Cells were cultured in 24-well plates with the addition of rapamycin, U0126, or DMSO as a control. After treatment, MTT (Thiazolyl Blue Tetrazolium Bromide, Sigma-Aldrich, Munich, Germany) was added to each well to a final concentration of $0.5 \mathrm{mg} / \mathrm{ml}$. After 3 hours, formazan crystals that formed from MTT in actively metabolizing cells were dissolved in lysis buffer containing 20\% SDS and 50\% DMF. Optical densities were measured at $570 \mathrm{~nm}$ using a scanning multiwell spectrophotometer (Thermo labsystem Multiscan EX).

\section{BrdU Proliferation Assay}

Cells were cultured in 24-well plates with the addition of rapamycin, U0126, or DMSO as a control. Cell Proliferation ELISA BrdU assay (Roche Diagnostics $\mathrm{GmbH}$, Mannheim, Germany) was used to estimate cell proliferation rate. Briefly, BrdU labeling solution was added to each well 6 hours before fixing and incubating with a mouse monoclonal anti-BrdU antibody conjugated with peroxidase. Next, 1 $\mathrm{mol} / \mathrm{L} \mathrm{H}_{2} \mathrm{SO}_{4}$ was added and optical densities were measured at $450 \mathrm{~nm}$ using a scanning multiwell spectrophotometer (Thermo labsystem Multiscan EX).

\section{Measurement of Cell Size}

Cells were cultured on glass slides with the addition of rapamycin, U0126, or DMSO as a control. Medium with 
$\begin{array}{llllllll}A & C 1 & C 2 & C 3 & 51 & 52 & S 3 & S 4\end{array}$

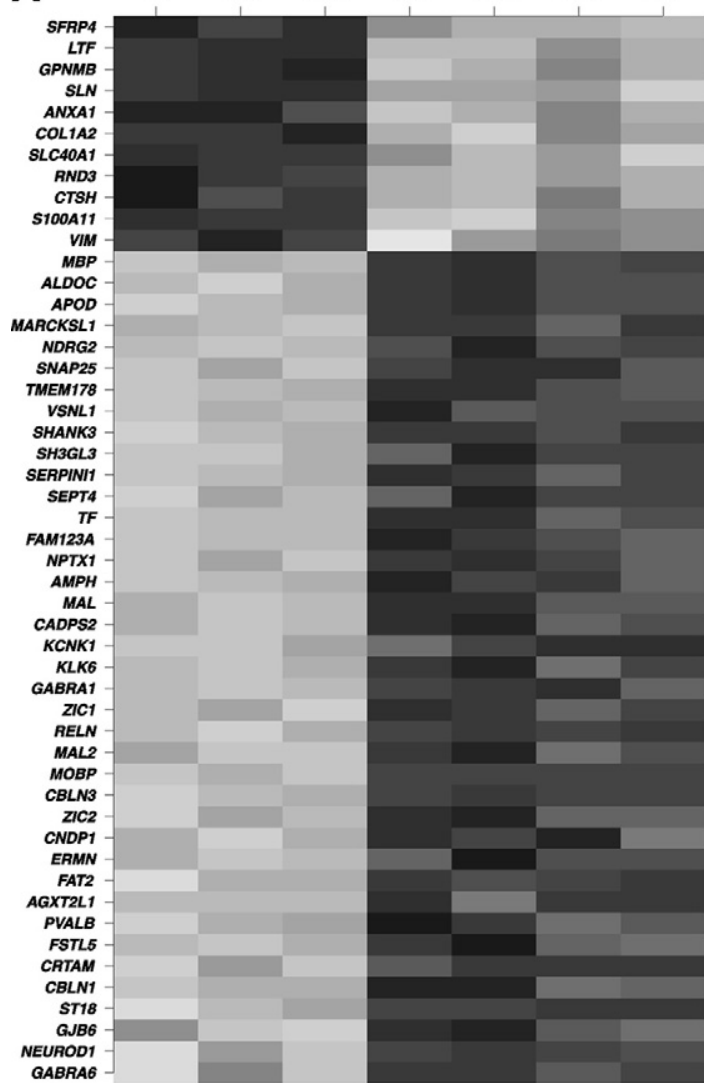

B

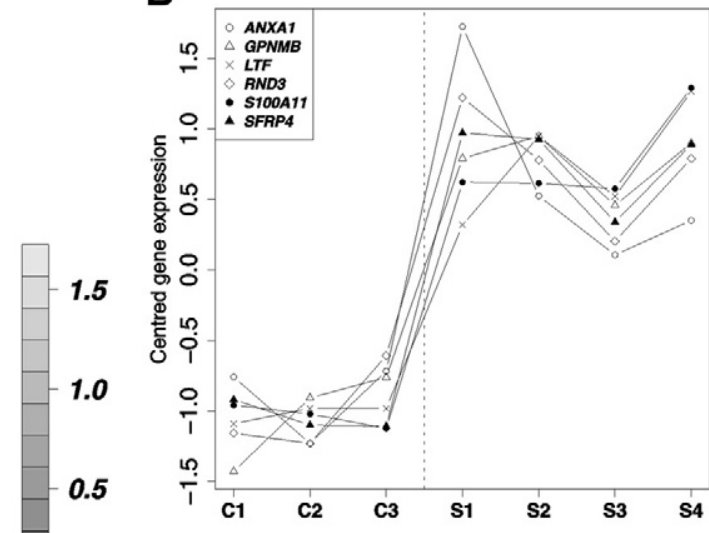

C

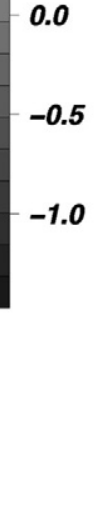

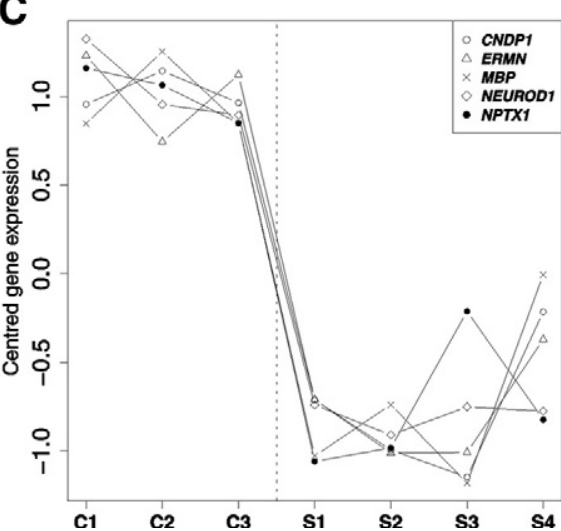

Figure 1. Microarray analysis of gene expression in SEGA and control brain. C1-3, control brain samples: C1 - control brain tissue from one donor, C2 - commercial control brain RNA pooled from 2 donors (Clontech), and C3 - commercial control brain RNA pooled from 23 donors (Ambion); S1-4, SEGA samples. A: Heat map representation of GC-RMA normalized microarray expression data for genes significantly altered in SEGA samples compared with control brain samples (q < 0.05). For a given gene an average value was computed and subtracted from each observation. Next, every value was divided by SD of all observations. B and C: Scatter plots of genes up- and down-regulated in SEGA compared with control brain, respectively, chosen for further studies according to literature data.

the inhibitors was changed every second day. After 6 days cells were fixed with $4 \%$ paraformaldehyde, stained with Phalloidin-TRITC $(0.1 \mu \mathrm{g} / \mathrm{ml}$, Sigma-Aldrich, Munich, Germany) for 1 hour, and mounted. Cells were viewed with a Leica SP5 laser confocal microscope (Leica, Mannheim, Germany) using the $561 \mathrm{~nm}$ line of the DPSS laser and a 20×, 0.7 an PlanApo oil-immersion objective. Optical sections were collected at $0.16-\mu \mathrm{m}$ increments, and 2D projections were made with the LAS AF software. Image stacks were processed using the 3D Constructor plug-in to ImagePro Plus 6.3 software. Individual cells were analyzed for cell volume and surface area.

\section{Scratch Assay}

Cells were cultured in 6-well plates and pre-incubated with rapamycin, U0126, or DMSO as a control for 3 hours before wounding the cells. Next, a scratch was created in the center of the cell monolayer using a pipette tip. Immediately thereafter, cells were washed with PBS to remove cellular debris and incubated with the inhibitors for additional 27 hours. The ability of cells to migrate into the scratch area was measured by counting of DAPI-stained nuclei along the scratch at 0 time point and after 30 hours of cell exposure to the inhibitors.

\section{Results}

\section{Identification of Genes Differentially Expressed in SEGA versus Control Brain with Microarray Analysis}

Gene expression profiling was performed on four SEGA samples from patients with TSC (S1-4), one control brain tissue (C1), and two commercial control brain RNA (C2 [from two donors] and C3 [from 23 donors]) using Affymetrix HG-U133 Plus 2.0 array sets. Figure 1 shows the results of microarray analysis obtained for probe sets called Present after the filtration as described in Materials and Methods. We first identified genes significantly altered in SEGAs versus control brain using false discovery rate of $<5 \%$, then we selected 50 differentially expressed genes with the biggest difference in expression level between SEGAs and control brain samples, and the highest similarity within these groups using the MultiExperiment Viewer 4.0 software (Figure 1A). A list of genes differentially expressed in SEGAs is shown in Table 1.

The 50 selected genes (11 up-regulated and 39 downregulated in SEGAs) were categorized into functional groups using the Ingenuity Pathway Analysis software. Based on their known biological functions, the genes were mainly involved in tumorigenesis (14 genes) and the ner- 
Table 1. Summary of Genes with Highest Up- or Down-Regulation Scores in SEGAs Compared with Control Brains

\begin{tabular}{|c|c|c|c|}
\hline Unigene & Gene symbol & Gene name & $\begin{array}{l}\text { Fold change } \\
\text { over controls }\end{array}$ \\
\hline \multicolumn{4}{|l|}{ Tumorigenesis } \\
\hline Hs.658169 & SFRP4 & secreted frizzled-related protein 4 & 2.514 \\
\hline Hs.610567 & $L T F$ & lactotransferrin & 2.197 \\
\hline Hs.190495 & GPNMB & glycoprotein (transmembrane) $\mathrm{nmb}$ & 2.139 \\
\hline Hs. 494173 & $A N X A 1$ & annexin $\mathrm{A} 1$ & 1.791 \\
\hline Hs.489142 & COL1A2 & collagen, type I, alpha 2 & 1.757 \\
\hline Hs.6838 & RND3 & Rho family GTPase 3 & 1.690 \\
\hline Hs. 148641 & $\mathrm{CTSH}$ & cathepsin $\mathrm{H}$ & 1.451 \\
\hline Hs.593414 & $S 100 A 11$ & s100 calcium binding protein a11 & 1.390 \\
\hline Hs.702229 & $A P O D$ & apolipoprotein D & 0.686 \\
\hline Hs.525205 & NDRG2 & NDRG family member 2 & 0.668 \\
\hline Hs. 444212 & VSNL1 & visinin-like 1 & 0.632 \\
\hline Hs. 287518 & SEPT4 & septin 4 & 0.580 \\
\hline Hs.591255 & FAT2 & FAT tumor suppressor homolog 2 (Drosophila) & 0.423 \\
\hline Hs.655499 & ST18 & suppression of tumorigenicity 18 & 0.386 \\
\hline \multicolumn{4}{|c|}{ Nervous system development } \\
\hline Hs.551713 & $M B P$ & myelin basic protein & 0.757 \\
\hline Hs.75061 & MARCKSL 1 & MARCKS-like 1 & 0.682 \\
\hline Hs. 167317 & SNAP25 & synaptosomal-associated protein, $25 \mathrm{kDa}$ & 0.660 \\
\hline Hs. 149035 & SHANK3 & SH3 and multiple ankyrin repeat domains 3 & 0.632 \\
\hline Hs. 270055 & SH3GL3 & SH3-domain GRB2-like 3 & 0.608 \\
\hline Hs. 478153 & SERPINI1 & neuroserpin & 0.607 \\
\hline Hs. 518267 & TF & transferrin & 0.573 \\
\hline Hs.702002 & NPTX1 & neuronal pentraxin I & 0.540 \\
\hline Hs.80395 & $M A L$ & mal, T-cell differentiation protein & 0.525 \\
\hline Hs.708214 & CADPS2 & Ca2+-dependent activator protein for secretion 2 & 0.521 \\
\hline Hs.79361 & $K L K 6$ & kallikrein-6 & 0.514 \\
\hline Hs. 175934 & GABRA1 & gamma-aminobutyric acid (GABA) A receptor, alpha 1 & 0.506 \\
\hline Hs. 647962 & ZIC1 & Zic family member 1 (odd-paired homolog, Drosophila) & 0.506 \\
\hline Hs.655654 & RELN & reelin & 0.504 \\
\hline Hs. 121333 & MOBP & myelin-associated oligodendrocyte basic protein & 0.463 \\
\hline Hs. 653700 & ZIC2 & Zic family member 2 (odd-paired homolog, Drosophila) & 0.451 \\
\hline Hs.400613 & CNDP1 & carnosine dipeptidase 1 (metallopeptidase M20 family) & 0.444 \\
\hline Hs.443894 & $E R M N$ & ermin, ERM-like protein & 0.431 \\
\hline Hs.591255 & FAT2 & FAT tumor suppressor homolog 2 (Drosophila) & 0.423 \\
\hline Hs.295449 & $P V A L B$ & parvalbumin & 0.412 \\
\hline Hs. 458423 & CBLN1 & cerebellin 1 precursor & 0.388 \\
\hline Hs.709709 & NEUROD1 & neurogenic differentiation 1 & 0.342 \\
\hline Hs. 90791 & GABRA6 & gamma-aminobutyric acid (GABA) A receptor, alpha 6 & 0.311 \\
\hline \multicolumn{4}{|l|}{ Others and unknown } \\
\hline Hs.334629 & $S L N$ & sarcolipin & 2.021 \\
\hline Hs. 643005 & SLC40A1 & solute carrier family 40, member 1 & 1.719 \\
\hline Hs.628678 & VIM & vimentin & 1.314 \\
\hline Hs. 155247 & ALDOC & aldolase C, fructose-bisphosphate & 0.708 \\
\hline Hs. 40808 & TMEM178 & transmembrane protein 178 & 0.634 \\
\hline Hs.528335 & FAM123A & family with sequence similarity $123 \mathrm{~A}$ & 0.555 \\
\hline Hs.592182 & $A M P H$ & amphiphysin & 0.538 \\
\hline Hs.208544 & KCNK1 & potassium channel, subfamily $\mathrm{K}$, member 1 & 0.519 \\
\hline Hs.201083 & MAL2 & mal, T-cell differentiation protein 2 & 0.473 \\
\hline Hs.207603 & CBLN3 & cerebellin 3 precursor & 0.463 \\
\hline Hs. 106576 & AGXT2L1 & alanine-glyoxylate aminotransferase 2 -like 1 & 0.422 \\
\hline Hs. 591707 & FSTL5 & fstl5 & 0.408 \\
\hline Hs. 159523 & CRTAM & cytotoxic and regulatory $T$ cell molecule & 0.407 \\
\hline Hs.511757 & GJB6 & gap junction beta- 6 protein & 0.381 \\
\hline
\end{tabular}

Genes used for further studies are printed in bold type.

vous system development (23 genes). Interestingly, all genes related to the nervous system development were down-regulated in SEGAs when compared with control brain samples (Table 1). Of the 50 genes, we chose 11 differentially expressed genes for further studies by a systematic PubMed search for genes with potential relevance to TSC biology and pathology. The expression pattern of these genes: six up- and five down-regulated in SEGAs showed evident differences between SEGAs and control brain samples (Figure 1, B and C). The selected genes up-regulated in SEGA: ANXA1, GPNMB, LTF, RND3, S100A11, and SFRP4 are involved in tumorigenesis, and genes down-regulated in SEGA: CNDP1, ERMIN, MBP, NEUROD1, and NPTX1 are potentially related to the nervous system development. Among them ANXA1, GPNMB, and NPTX1 were previously shown to be differentially expressed in Tsc2 null murine neuroepithelial progenitor cells compared with wild-type neuroepithelial progenitor cells. ${ }^{20}$ 
Real-Time PCR Verification of Differentially Regulated Genes and Immunohistochemical Detection of ANXA1, GPNMB, and S100A11 in SEGA Tissue Sections

To verify the results of microarray analysis, we performed real-time PCR and immunohistochemical validation, wherever antibody was available, mostly on an independent set of tumor samples. We selected 11 differentially expressed genes for a quantitative validation using real-time PCR. Analysis was performed on 10 SEGAs and 5 control brain samples and included tumor samples used for microarray analysis and additional samples from different individuals: six SEGAs and two control brain samples. As shown in Figure 2, real-time PCR confirmed the findings of the microarray experiment, with ANXA1, GPNMB, LTF, RND3, S100A11, and SFRP4 mRNAs up-regulated in SEGAs and CNDP1, ERMIN, MBP, NEUROD1, and NPTX1 mRNAs down-regulated in SEGAs. Differences in the levels of expression between SEGAs and control brains were significant for all tested genes $(P<0.05$, Figure 2, A and $B$ ) and paralleled those observed in the microarray study.

We evaluated ANXA1, GPNMB, and S100A11 expression immunohistochemically on a panel of SEGA tissue sections with commercially available antibodies. A staining was performed on paraffin-embedded SEGAs from five TSC patients (distinct from those used in the microarray and real-time PCR experiments) and five non-tumoral brain tissue samples. Representative micrographs in Figure 3 show that all tested SEGA tissues were immunoreactive for ANXA1, GPNMB, and S100A11, and the levels of studied proteins were higher in SEGA relative to the non-tumoral brain. Cell membrane and cytoplasmic ANXA1 and GPNMB staining was detected in all SEGA samples, mostly in giant cells (Figure $3, A$ and $B$, left panels, arrows). On the other hand, S100A11 expression was apparently both cytoplasmic and nuclear (Figure 3C, left panel). Only a faint staining was observed in non-tumoral brain tissue samples (Figure 3, A, B, and C, right panels). Negative controls without primary antibodies showed no positive staining (Figure 3D). The results demonstrate an increased expression of ANXA1, GPNMB, and S100A11 proteins in SEGAs compared with control brain consistently with up-regulation of these genes expression.

\section{Genes Differentially Expressed in SEGA Samples Have Similar Expression Profile in SEGA-Derived Cell Cultures}

To examine a role of mTOR signaling in the expression of identified genes, we established primary cell cultures derived from SEGAs from three TSC patients. First, we investigated whether the expression of the 11 selected genes in cultured SEGA cells was comparable with the pattern observed in SEGA samples. We performed realtime PCR analysis using RNA isolated from SEGA cells
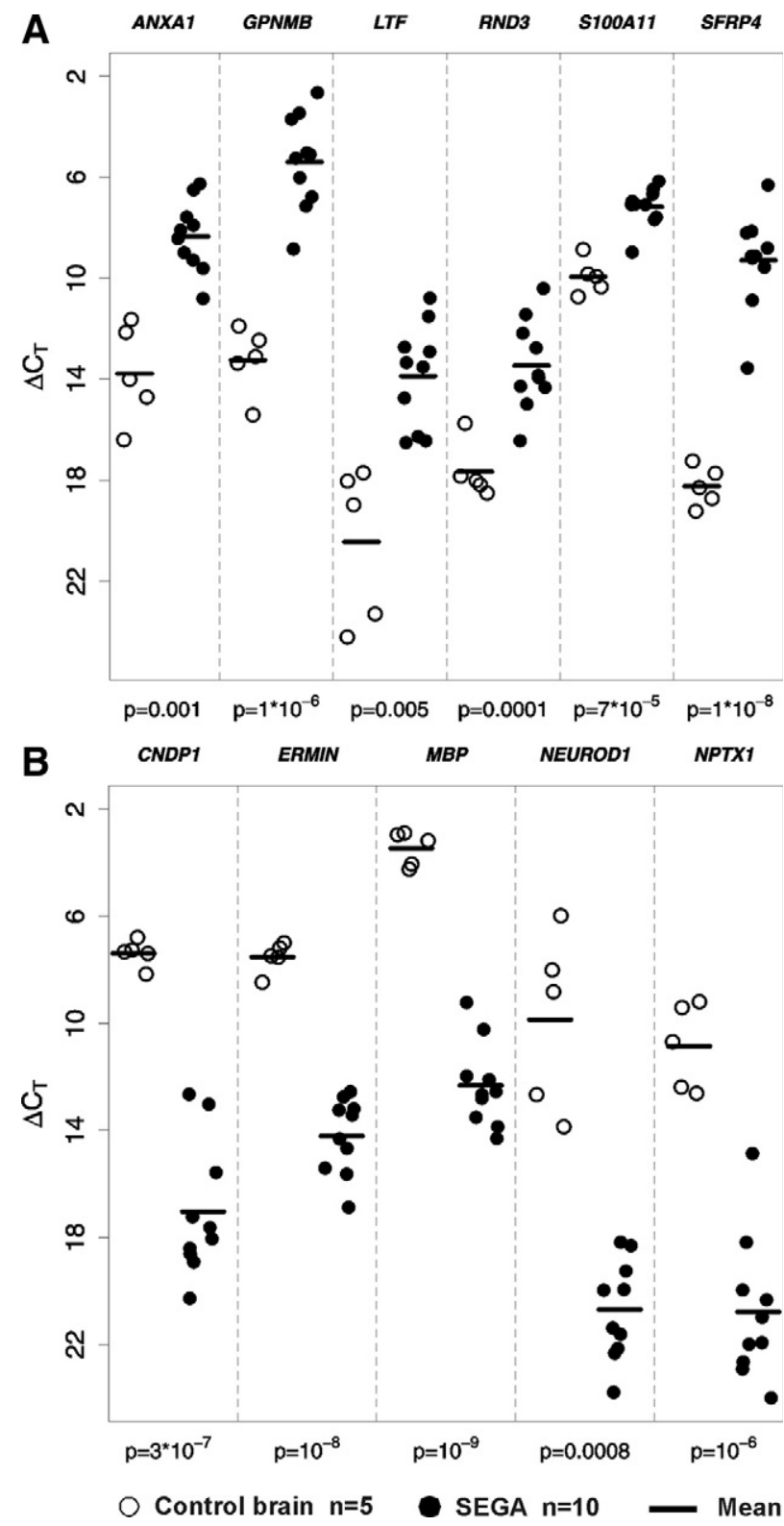

Figure 2. Real-time PCR validation of candidate genes in SEGAs and control brain samples. $\mathbf{A}$ and $\mathbf{B}$ : The difference in expression of up- and down-regulated genes in SEGAs compared with control brain samples was confirmed on samples used for microarray analysis, six additional SEGAs, and two additional nontumoral control brain samples from nonTSC patients. Lower $\Delta \mathrm{C}_{\mathrm{T}}$ are consistent with higher gene expression. Statistical analysis was done by Student $t$ test, $P<0.05$ are considered to be significant.

and five control brain samples used previously in the microarray and real-time PCR experiments. We found that the levels of ANXA1, GPNMB, LTF, RND3, S100A11, and SFRP4 mRNAs were higher (Figure 4A) and those of CNDP1, ERMIN, MBP, NEUROD1, and NPTX1 were lower in SEGA cells (Figure 4B). Differences in the levels of expression between SEGA-derived cell cultures and control brains were statistically significant for all tested genes. It confirmed that expression profiles of these genes were similar in the homogenous population of cultured SEGA cells, as well as in the whole tumor samples. 


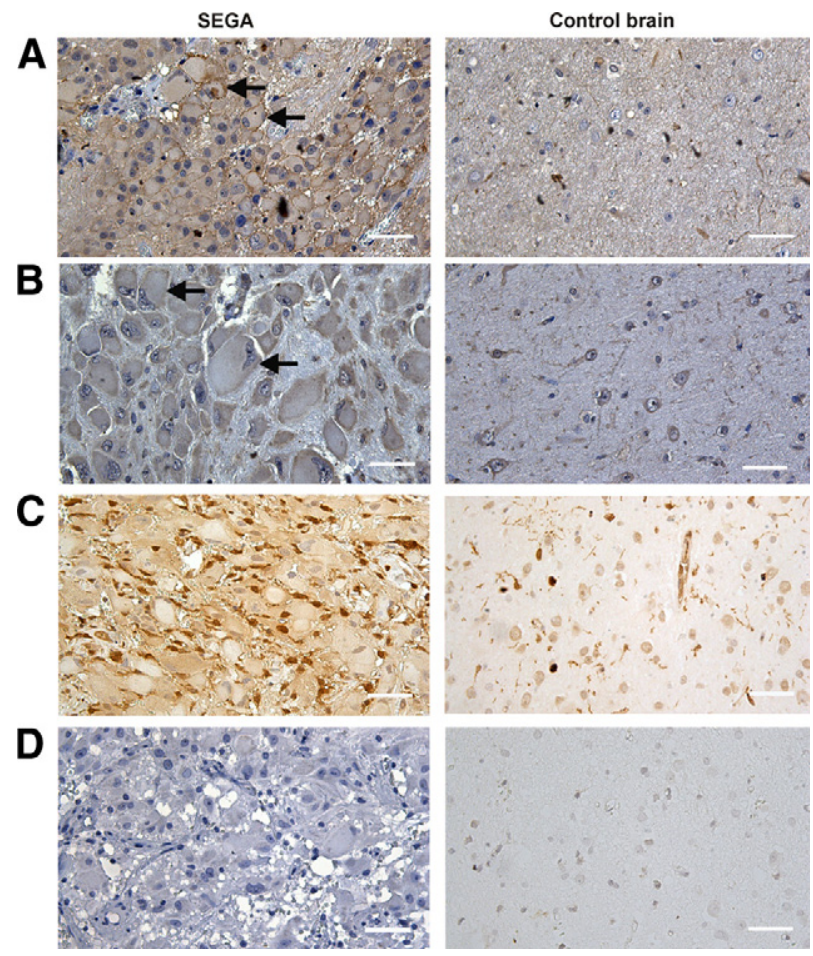

Figure 3. Immunohistochemical validation of selected markers expression in SEGA cells and control brain tissues. Representative images show a positive 3,3'-diaminobenzidine (DAB) staining (brown) for ANXA1 (A), GPNMB (B), and S100A11 (C) in SEGA cells (left panels). D: negative controls without primary antibodies. Nuclei were counterstained with hematoxylin (blue). Arrows indicate giant cells. The expression of studied proteins was confined to tumor cells. Scale bar $=50 \mu \mathrm{m}$.

\section{Expression of Tumorigenesis-Related Genes and MBP Is Increased in SEGA Cells in Comparison with Normal Human Astrocytes}

The cell origin of SEGA is unknown and controversial. Although the tumors are classified as astrocytomas, they seem to have a mixed glioneuronal lineage and express both neuronal and glial markers. ${ }^{1}$ We compared expression of the newly identified genes in three SEGA-derived cell cultures to their expression patterns in NHA. Cultured NHA resemble SEGA cells morphologically, however SEGA giant cells are bigger than normal astrocytes (Figure 5A). Moreover, SEGA cells were immunoreactive for glial fibrillary acidic protein used as a marker of astrocytes (data not shown). We found that the majority of tested genes (6 of 11) - ANXA1, GPNMB, LTF, RND3, S100A11, and SFRP4-showed the same expression patterns in SEGA cells versus NHA as versus control brain. Furthermore, the expression of ANXA1, GPNMB, LTF, RND3, S100A11, SFRP4, and MBP was greatly elevated in SEGA cell cultures when compared with normal human astrocytes. Briefly, SFRP4 expression was $\approx 300$ times $(P=0.0480), L T F>200$ times $(P=0.0267)$, GPNMB $\approx 100$ times $(P=0.0052), M B P \approx 50$ times $(P=$ 0.0428), RND3 $\approx 30$ times $(P=0.0022)$, and ANXA1 $(P=$ $0.0103)$ and $S 100 A 11 \approx 10$ times $(P=0.0001)$ increased in SEGA-derived cells compared with NHA (Figure 5B). Our results indicate that normal human astrocytes are an appropriate control for cultured SEGA cells.
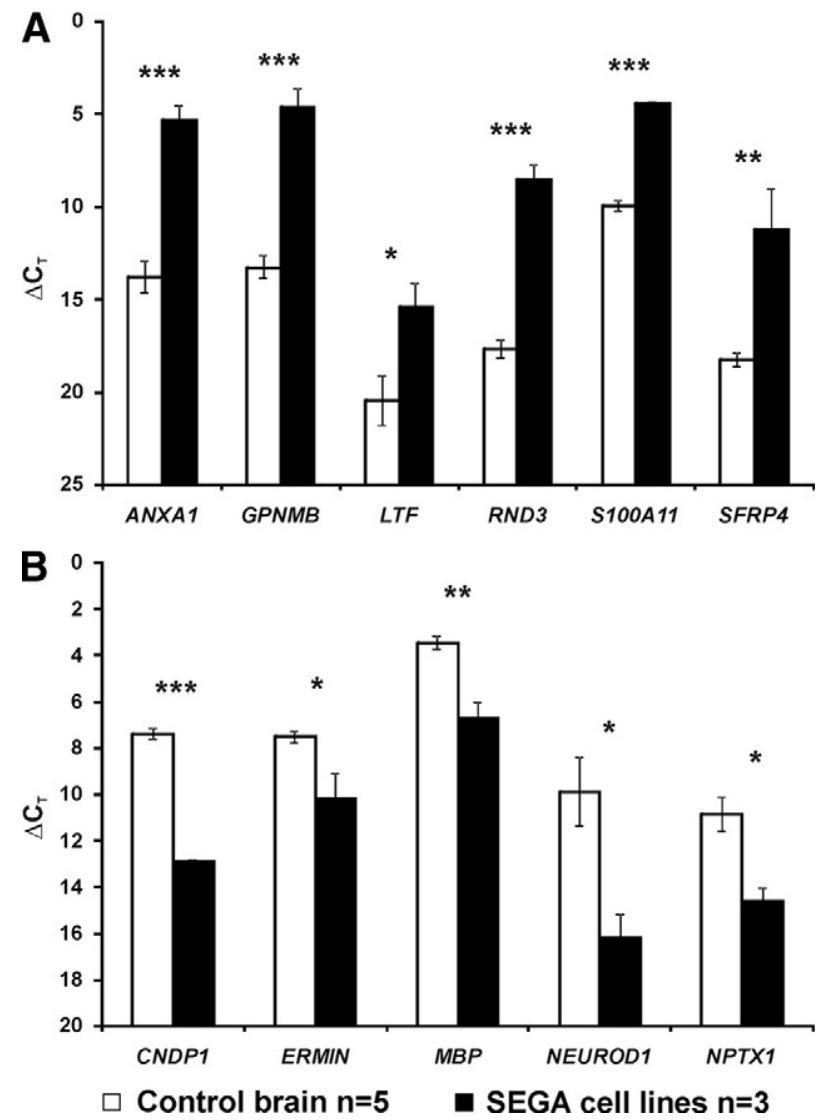

Figure 4. Real-time PCR validation of candidate genes in primary SEGA cell cultures and control brain. $\mathbf{A}$ and $\mathbf{B}$ : The difference in expression of genes up- and down-regulated in SEGA cells compared with control brain samples, respectively. Bars represent means \pm SEM of five control brain samples and three SEGA cell lines. Lower $\Delta \mathrm{C}_{\mathrm{T}}$ values are consistent with higher gene expression. Statistical analysis was done by Student $t$ test, ${ }^{*} P<0.05$, ${ }^{* * *} P<$ $0.01,{ }^{* * * *} P<0.001$

\section{Inhibition of mTOR Activity Alters Expression Levels of Selected Genes in SEGA Cells But Not in Normal Human Astrocytes}

To investigate the influence of mTOR on the regulation of selected genes expression, the mTOR kinase activity was inhibited in SEGA cells and normal human astrocytes using rapamycin. We observed that the levels of phospho-S6 kinase and its substrate phospho-S6 were significantly higher in SEGA cells than in NHA cultures. Moreover, rapamycin at concentration $10 \mathrm{nmol} / \mathrm{L}$ inhibited the kinase activity of mTOR and reduced the S6 kinase and S6 phosphorylation in SEGA cells, whereas the treatment had no influence on the levels of phosphorylation of these proteins in NHA (Figure 5C). Therefore, we sought to examine whether inhibition of mTOR activity would have a greater effect on the expression of genes regulated by mTOR in SEGA cells than in normal human astrocytes. The expression of 11 genes in SEGA and NHA was determined 24 hours after exposure to $10 \mathrm{nmol} / \mathrm{L}$ rapamycin. The reduction of mRNA levels of six genes highly up-regulated in SEGAs was observed along with the increase of NPTX1 expression in the drug-treated SEGA cells. Briefly, we observed $\approx 3$-fold decrease in $\operatorname{LTF}(P=$ 
A
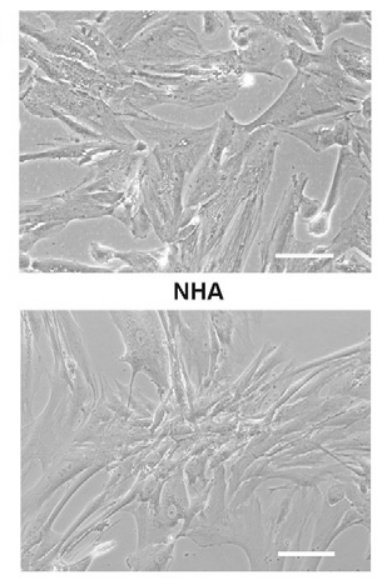

SEGA cells

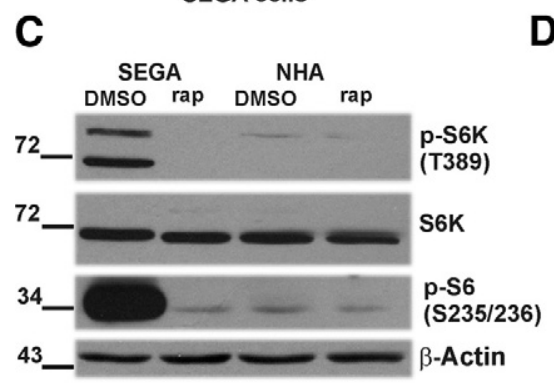

B

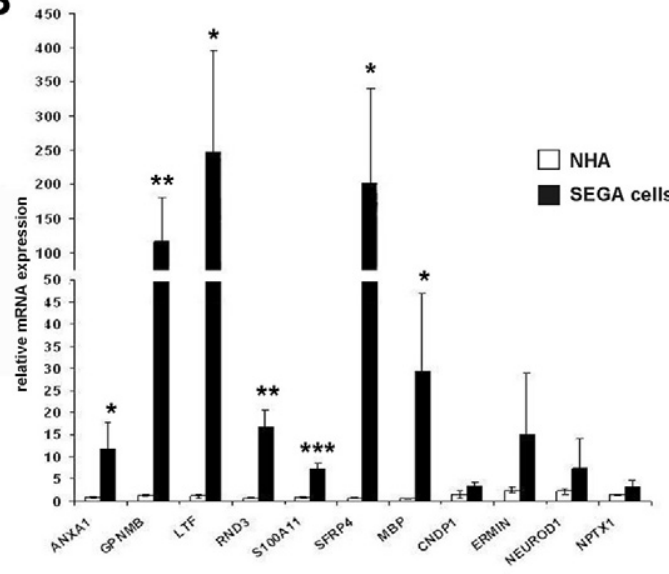

D

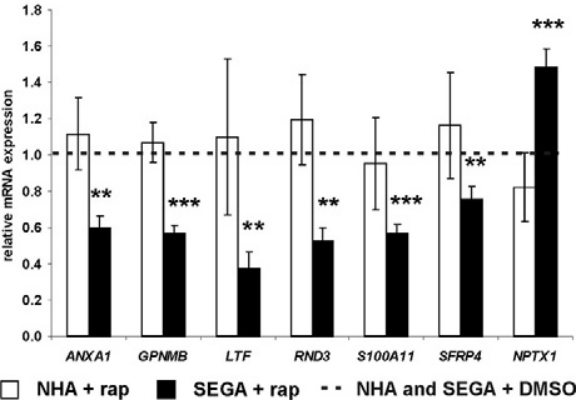

Figure 5. Rapamycin alters the expression of ANXA1, GPNMB, LTF, RND3, S1OOA11, SFRP4 and NPTX1 in SEGA cells but not in normal human astrocytes. A: Phase-contrast images of normal human astrocytes (NHA) and cultured SEGA-derived cells. Scale bar $=100 \mu \mathrm{m}$. B: Real-time PCR analysis of candidate genes expression in NHA and SEGA-derived cells. Bars represent means \pm SEM of the mRNA levels of each gene in SEGA cells (means of three independently derived SEGA cell lines) relative to those expressed in NHA (means of three cell cultures). Statistical analysis was done by Student $t$ test, ${ }^{*} P<0.05,{ }^{* *} P<0.01,{ }^{* * * *} P<0.001$. C Representative Western blot analysis of phospho-S6K (T389) and phospho-S6 (S235/236) levels in SEGA-derived cell cultures and NHA after treatment with $10 \mathrm{nmol} / \mathrm{L}$ rapamycin for 24 hours. S6K and $\beta$-Actin served as protein loading controls. D: Real-time PCR analysis of expression levels of ANXA1, GPNMB, LTF, RND3, S1OOA11, SFRP4, and NPTX1 in three SEGAderived cell cultures and NHA cells after rapamycin treatment. The mRNA levels of investigated genes in cells treated with rapamycin were related to their expression in control (DMSOtreated) cells. Bars represent means \pm SEM of three independent experiments. Statistical analysis was done by Student $t$ test, ${ }^{* *} P<0.01$, ${ }_{* * * * *} P<0.001$
0.0018), $\approx 2$-fold decrease in ANXA1 $(P=0.0024)$, $\operatorname{GPNMB}(P=0.0002), R N D 3(P=0.0013)$, and S100A11 $(P=0.0003)$, and $\approx 1.5$-fold decrease in SFRP4 ( $P=$ $0.0092)$ expression levels in SEGA cells exposed to rapamycin. Furthermore, the treatment increased the expression of NPTX1 by $\approx 1.5$ fold $(P=0.0007)$ in these cells. On the other hand, according to our assumption, the expression levels of the investigated genes were not significantly changed in NHA after rapamycin treatment (Figure 5D). These results demonstrate that the expression of ANXA1, GPNMB, LTF, RND3, S100A11, SFRP4, and NPTX1 is regulated by mTOR signaling pathway in SEGA cells.

\section{mTOR and ERK Signaling Pathways Regulate Proliferation, Size, Morphology, and Migration of SEGA Cells}

Recent studies demonstrate that, in addition to mTOR, ERK signaling pathway is activated in the TSC brain lesions. $^{27-29}$ To investigate a role of mTOR and ERK signaling in pathology of SEGA, primary SEGA cell cultures were treated for 3 hours with $10 \mathrm{nmol} / \mathrm{L}$ rapamycin or $40 \mu \mathrm{mol} / \mathrm{L}$ U0126 (an inhibitor of MEK1/2 kinase activity) alone or in combination. The corresponding dose of DMSO was added to control cells. Rapamycin or U0126 completely inhibited mTOR and MEK1/2 kinase activities, which was estimated by the lack of phosphorylated substrates of the kinases: phospho-S6K and phosphoERK1/2, respectively. Neither of the inhibitors affected the other signaling pathway (Figure 6A). Because both pathways transmit the prosurvival signals, we investi- gated viability and proliferation of SEGA cells after treatment with the inhibitors. The $\approx 30 \%$ decrease of the number of living cells was observed after 72 hours exposure of SEGA cells to rapamycin and U0126 added in combination to culture media ( $P=0.002$ ), as was determined using MTT metabolism test. Rapamycin or U0126 alone had no significant effects on viability of SEGA cells (Figure 6B). Furthermore, U0126 alone and together with rapamycin inhibited the proliferation of SEGA cells by $\approx 30 \%(P=0.046)$ and $\approx 40 \%(P=0.005)$, respectively. Rapamycin alone did not affect cell proliferation (Figure 6C).

Because mTOR hyperactivity is responsible for cell overgrowth and ERK signaling has been shown to control remodeling of actin cytoskeleton and cell motility, ${ }^{30,31}$ we studied the influence of rapamycin and U0126 on morphology and migration of SEGA cells. Figure 6D shows staining of actin cytoskeleton in SEGA cell cultures 6 days after exposure to rapamycin or/and U0126. Profound changes in cellular morphology were observed after U0126 treatment (cells became more round than elongated) with a distinctive arrangement of actin filaments, which was even more noticeable on concomitant treatment with rapamycin and U0126. Rapamycin alone had no apparent influence on the shape of SEGA cells. However, the measurement of SEGA cell size with confocal microscopy and the Image-Pro Plus 6.3 software demonstrated a decrease of cell volume by $\approx 50 \%$ ( $P=$ $0.0002)$ and cell area by $40 \%(P=0.0004)$ after 6 days of exposure to rapamycin. Similar results were observed after concomitant treatment with rapamycin and U0126: volume and area of SEGA cells were reduced by $\approx 40 \%$ 
A

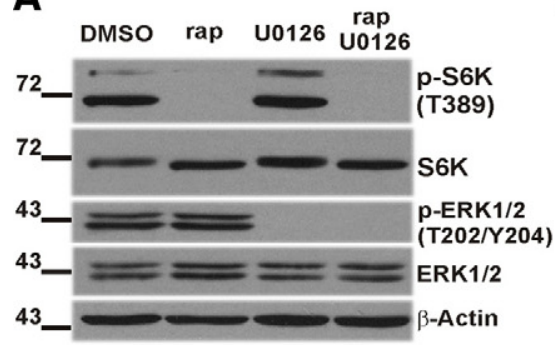

D

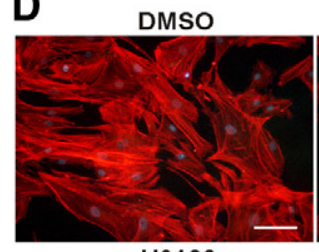

U0126
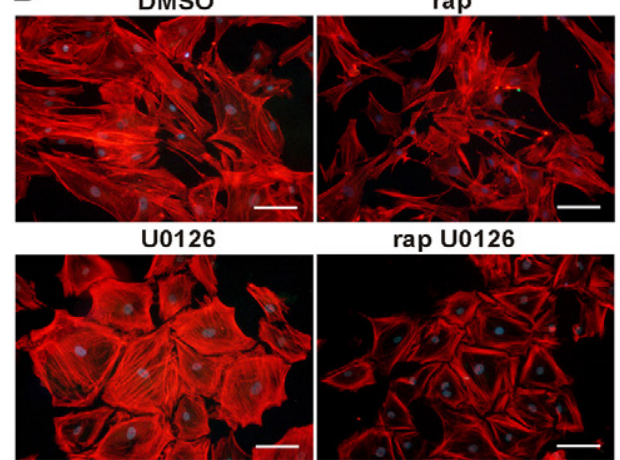

rap U0126

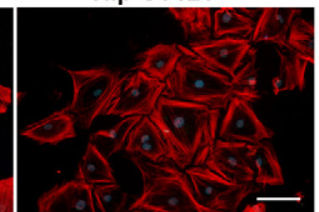

B

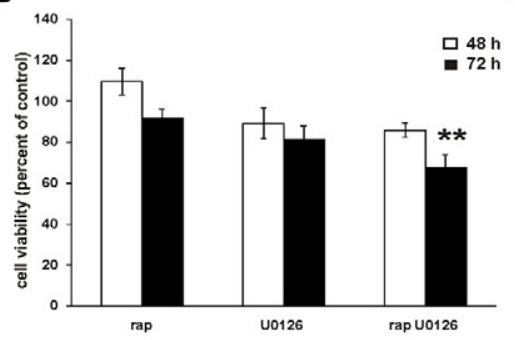

C

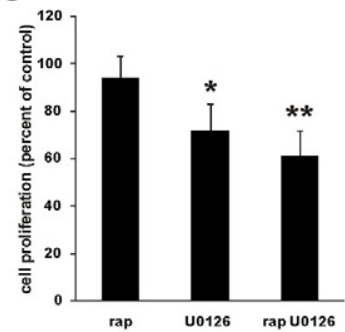

E

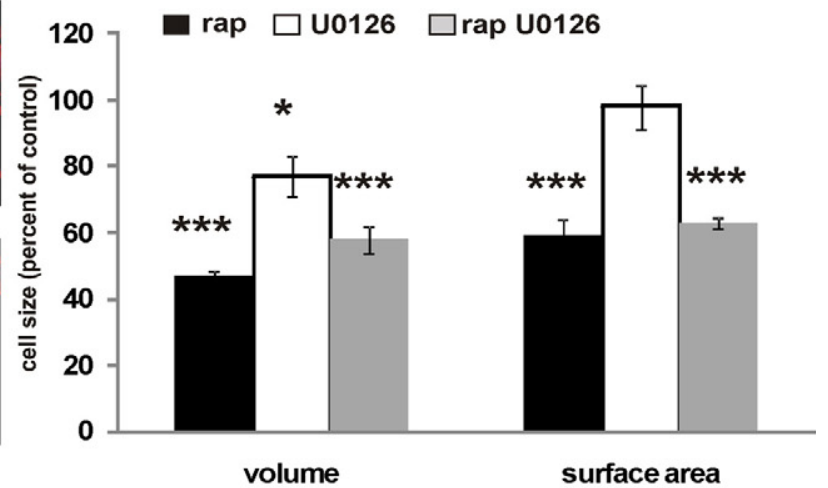

$\mathbf{F}$

DMSO

rap

U0126

rap U0126

$\mathbf{O h}$
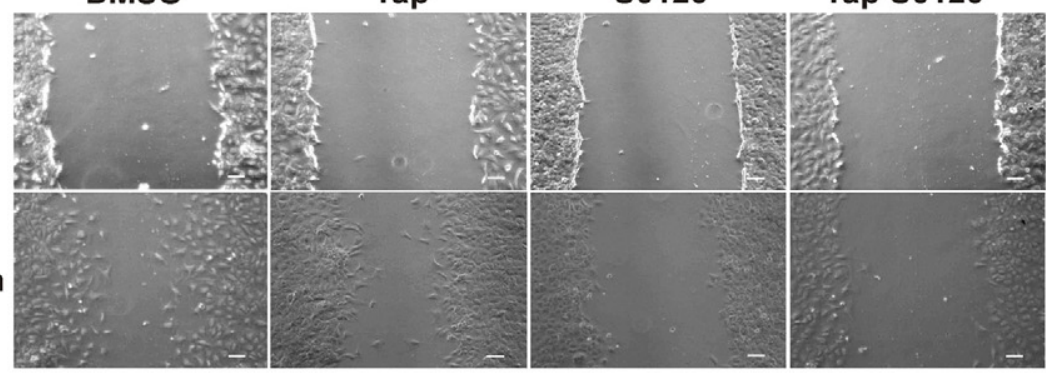

G

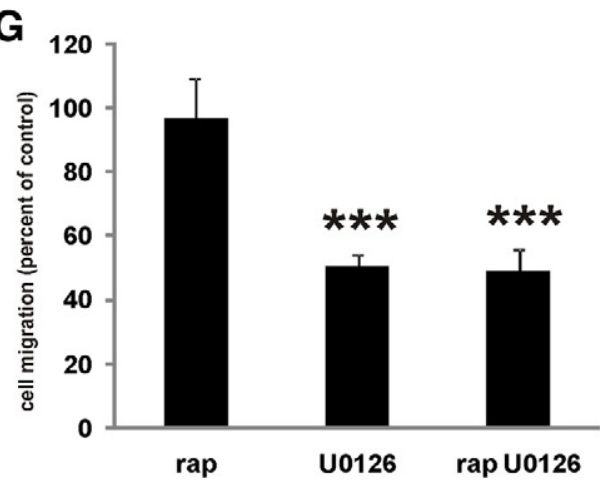

H
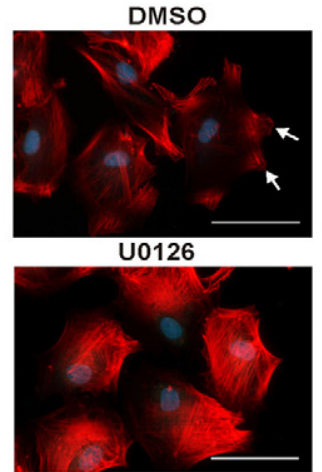

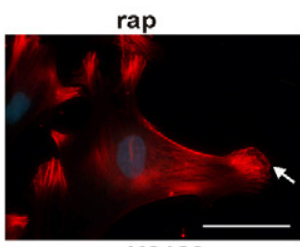

rap U0126

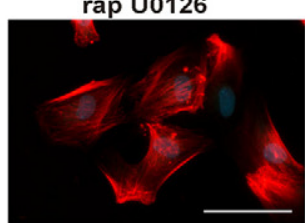

Figure 6. Combined inhibition of mTOR and ERK signaling pathways affects proliferation, shape, size, and migration of SEGA-derived cells. A: Western blot analysis of the levels of phospho-S6K (T389), S6K, phospho-ERK1/2 (T202/Y204), ERK1/2, and $\beta$-Actin in SEGA-derived cells 3 hours after treatment with 10 $\mathrm{nmol} / \mathrm{L}$ rapamycin or/and $40 \mu \mathrm{mol} / \mathrm{L}$ U0126. DMSO was used as a control. B: Cell viability was determined 48 and 72 hours after exposure to rapamycin or/and U0126 using MTT metabolism test. Bars represent viability of cells treated with the inhibitors related to control cells (means \pm SEM of four independent cell cultures, each in triplicate). C: Cell proliferation was determined 48 hours after exposure to rapamycin or/and U0126 using BrdU test. Bars represent the percentage of proliferating cells treated with the inhibitors related to control cells (means \pm SEM of four independent cell cultures, each in triplicate). D: Representative images show fluorescent phalloidin staining of the actin cytoskeleton in SEGA cells 6 days after exposure to rapamycin or/and U0126. Nuclei were stained with 4',6-diamidino-2-phenylindole (DAPI). Scale bar $=100 \mu \mathrm{m}$. E: Cell size was analyzed by confocal microscopy in phalloidin- and DAPI-stained SEGA cell cultures 6 days after exposure to rapamycin or/and U0126 and quantified with Image-Pro Plus 6.3 software. Bars represent the percentage of volume and surface area of cells treated with the inhibitors related to control cells (means \pm SEM of two independent cell cultures, $\approx 150$ randomly selected cells per condition). F: Scratch assay - representative phase-contrast images along the scratch area at 0 time point and after 30 hours of exposure of SEGA cells to rapamycin or/and U0126. Scale bar $=100 \mu \mathrm{m}$. G: Cell migration into the wound area was estimated at 27 hours after scratching by counting of DAPI-stained nuclei along the scratch. Bars represent the percentage of nuclei of cells treated with the inhibitors related to control cells (means \pm SEM of three independent cell cultures, each in duplicate, ten nonoverlapping microscopic fields at each well were analyzed). H: Representative images show fluorescent phalloidin staining of the actin cytoskeleton of SEGA cells along the scratch 30 hours after exposure of cells to rapamycin or/and U0126. DMSO was used as a control. Arrows indicate lamellipodia at the leading edges of migrating cells. Nuclei were stained with DAPI. Scale bar $=100 \mu \mathrm{m}$. Statistical analysis was done by one-way analysis of variance followed by Newman-Keuls test, ${ }^{*} P<0.05,{ }^{* * *} P<0.01,{ }^{* * * * *} P<0.001$. 
$(P=0.0003)$. U0126 alone did not affect size of SEGA cells area and had a slight effect on their volume $(\approx 20 \%$ decrease, $P=0.01$; Figure $6 \mathrm{E}$ ). To assess an influence of the inhibitors on migration of SEGA cells into the wound area, we performed scratch assay. As shown in Figure 6, $F$ and $G$, U0126 decreased a number of migrating cells by $51 \%$ after 30 hours of treatment $(P=0.0003)$. Exposure to both drugs in combination produced very similar results (inhibition of cell migration by $50 \%, P=0002$ ), indicating that mTOR signaling does not participate in this process in SEGA cells. This was also confirmed by the lack of any effect on migration after an exposure to rapamycin alone. These results were in agreement with the observed formation of lamellipodia consisting of branched actin filaments at the leading edges of migrating cells mainly in control and rapamycin-treated cells (Figure 6H). The data show that inhibiting of both mTOR and ERK signaling pathways results in the most significant changes in SEGA cell growth.

\section{Discussion}

The present study shows the results of the first genomewide expression profiling on SEGAs-brain tumors occurring in TSC, a disease characterized by the aberrant activity of mTOR kinase. We performed microarray analysis, real-time PCR, and immunohistochemistry to identify genes that are differentially expressed in SEGA compared with nontumoral brain. We used a relatively small number of SEGA samples for global gene profiling, therefore the microarray data analysis was very restrictive. Human control brain RNAs are difficult to obtain, thus we used the commercial human brain reference RNA pooled from 23 or 2 donors to increase the total number of control samples in the microarray experiment. The whole brain controls were considered a better choice than those collected from specific brain regions, because SEGAs have a mixed glioneuronal lineage. Moreover, as we aimed at the identification of genes which expression was modulated by the aberrantly active TSC1/2-mTOR signaling pathway, it was essential to obtain controls from non-TSC donors. Of the fifty genes identified as differentially expressed in SEGA, the expression of eleven genes selected for further studies was altered in six additional SEGAs from independent TSC patients compared with control brain samples, as was validated by real-time PCR. Seven genes: ANXA1, GPNMB, LTF, RND3, S100A11, SFRP4, and NPTX1 were shown to be mTOR effector genes in SEGA-derived cell cultures, because treatment with rapamycin (an inhibitor of mTOR) modulated their expression. Microscopic analysis of stained sections confirmed overexpression of Annexin A1, GPNMB, and S100A11 in tumor samples from five different TSC patients.

Identified genes encode proteins that fall into two major categories: proteins involved in tumorigenesis, upregulated in SEGA and proteins implicated in the nervous system development/differentiation, down-regulated in SEGA. Genes up-regulated in SEGAs and dependent on the mTOR signaling have been shown to be involved in progression or suppression of various tumors. Annexin A1 (ANXA1), a calcium- and phospholipid-binding protein with anti-inflammatory properties, plays roles in diverse cellular functions, such as membrane aggregation, inflammation, phagocytosis, proliferation, and apoptosis. ANXA1 was up-regulated in astrocytomas or pancreatic cancers. $^{32-33}$ On the other hand, down-regulation of ANXA1 was reported in many types of cancers, including head and neck and breast cancers. ${ }^{34-35}$ Annexin A1 interacts with S100A11 (also called calgizzarin or $\mathrm{S} 100 \mathrm{C}$ ), an EF hand-type $\mathrm{Ca}^{2+}$ binding protein of the S100 family of proteins. S100A11 plays distinct roles depending on the type of tumor. ${ }^{36}$ In bladder and renal cancers, the expression of S100A11 was related to tumor suppression, ${ }^{37,38}$ but in prostate and breast cancers to tumor promotion. ${ }^{39-40}$ Intranuclear localization of S100C/ S100A11 was implicated in the contact inhibition of fibroblasts and HeLa cell growth. ${ }^{41}$ Next, glycoprotein nonmetastatic melanoma protein B (GPNMB) was shown to be highly expressed in malignant gliomas and in metastatic breast cancer. ${ }^{42-43}$ GPNMB is suggested to be an adhesion molecule mediating intercellular interactions and contributing to the acquisition of the invasive nature of malignant tumor cells. However, it was also reported to be up-regulated in low metastatic melanoma cell lines. ${ }^{44}$

Furthermore, LTF, RND3, and SFRP4 are other genes identified in the present study and having potential tumor suppressor activity. Lactotransferrin (LTF), a transcription factor which modulates cell growth and a variety of cellular and immune responses, ${ }^{45}$ is down-regulated in malignant gliomas and nasopharyngeal carcinoma. ${ }^{46,47}$ Similarly, Rho family GTPase 3 (RND3), a protein involved in organization of actin cytoskeleton and cell cycle regulation, ${ }^{48}$ was observed to inhibit cell cycle progression and induce apoptosis in glioblastoma and prostate cancer cells, ${ }^{49-50}$ which may imply its role as a tumor suppressor protein. Secreted frizzled-related protein 4 (SFRP4), an antagonist of Wnt pathway controlling cell proliferation, differentiation, and migration, was downregulated in endometrial cancers and chronic lymphocytic leukemia. ${ }^{51,52}$ We postulate here that Annexin A1, GPNMB, S100A11, LTF, RND3, and SFRP4 are candidate markers of subependymal giant cell astrocytomas. GPNMB, LTF, RND3, and SFRP4 may be responsible for benign phenotype and relatively low invasiveness of these tumors.

A second category consists of genes which are downregulated in SEGA and encode proteins implicated in the nervous system development and differentiation. Our study revealed reduced expression of many genes encoding oligodendrocyte-specific proteins such as myelin basic protein (MBP), myelin-associated oligodendrocyte basic protein, transferrin, or ermin, a marker of myelinating oligodendrocytes that binds to filamentous actin and regulates cell morphology. ${ }^{53} \mathrm{Next}$, expression level of neuronal pentraxin 1 (NPTX1), an early neuronal lineage marker shown to take part in the synapse formation and remodeling, ${ }^{54,55}$ was also downregulated in SEGAs. Furthermore, neurogenic differentiation 1 (NeuroD1/BETA2), a member of the bHLH transcription factor family, emerges to be a gene of particular 
importance. It is known to influence the fate of specific neuronal, endocrine, and retinal cells ${ }^{56,57}$ and plays a pivotal role in terminal differentiation of neural progenitors. ${ }^{58}$ Overexpression of human NeuroD1 in fetal glial cell line resulted in appearance of the early neuronal development markers. ${ }^{59}$ It is possible that reduced expression of these genes might be related to the postulated defects in differentiation and mixed glioneuronal origin of SEGA. Moreover, NeuroD1-null mice were shown to develop malformations in the dentate gyrus and exhibit spontaneous limbic seizures. ${ }^{60}$ Carnosine dipeptidase 1 (CNDP1) was another protein with reduced expression in SEGA, which has been associated with neuropathological processes. CNDP1 deficiency was reported in syndromes characterized by mental retardation, developmental delay, seizures, neurosensory hearing loss, or progressive childhood dementia. ${ }^{61,62}$ Down-regulation of these genes might be linked with the occurrence of neurological dysfunctions, such as seizures or mental retardation, among TSC patients.

A role of mTOR signaling in the regulation of expression of identified genes was studied in primary SEGA cell cultures derived from three TSC patients. We observed that the genes had the same expression patterns in SEGA cells as in tumor samples in comparison with the control brain and normal human astrocytes. We observed that elevated expression of genes related to tumorigenesis was reduced by inhibition of mTOR signaling with rapamycin in SEGA cells. The expression level of neuronal pentraxin 1 was elevated after exposure to the drug.

The previous study performed on a single SEGA cell line indicated that $20 \mathrm{nmol} / \mathrm{L}$ rapamycin inhibited cell viability after 24 hours of treatment. ${ }^{27}$ However, our results, reproduced on three independent SEGA cell lines, showed that inhibition of mTOR activity did not affect SEGA cell viability and proliferation even after six days of exposure to rapamycin. Furthermore, rapamycin did not influence either SEGA cell migration or actin cytoskeleton arrangement, but it decreased SEGA cell size. This observation is in agreement with a hypothesis that mTOR is responsible for SEGA giant cell overgrowth. On the other hand, we also showed that the inhibition of MEK1/2 activity with U0126 diminished proliferation of SEGA cells without affecting their survival. Moreover, it significantly decreased SEGA cell migration. Reduction of ERK1/2 phosphorylation did not influence SEGA cell size but it changed their shape by modulation of actin cytoskeleton. Combined suppression of mTOR and ERK signaling pathways resulted in the most remarkable decrease of SEGA cell viability, proliferation, and actin cytoskeleton rearrangement. These results suggest that mTOR and ERK signaling pathways may be responsible for pathogenesis and progression of SEGA. Combined inhibition of both pathways should be considered as a promising strategy for treatment of tumors harboring deregulation of these pathways.

In conclusion, this is the first report to show genes differentially expressed in subependymal giant cell astrocytomas when compared with the control brain. Moreover, we identified seven novel genes in the human brain dependent on mTOR kinase at the transcriptional level.
These genes should be further investigated as potential diagnostic biomarkers or target genes for the development of effective therapeutics. Furthermore, we suggest that targeting at both mTOR and ERK signaling pathways may give better results in the treatment of SEGAs than using mTOR inhibitors alone.

\section{Acknowledgments}

We thank Dr. Aleksandra Ellert-Miklaszewska and Dr. Agata Gozdz for critical reading of the manuscript and helpful suggestions.

\section{References}

1. Hirose T, Scheithauer BW, Lopes MB, Gerber HA, Altermatt HJ, Hukee MJ, VandenBerg SR, Charlesworth JC: Tuber and subependymal giant cell astrocytoma associated with tuberous sclerosis: an immunohistochemical, ultrastructural, and immunoelectron and microscopic study. Acta Neuropathol 1995, 90:387-399

2. Buccoliero AM, Franchi A, Castiglione F, Gheri CF, Mussa F, Giordano F Genitori L, Taddei GL: Subependymal giant cell astrocytoma (SEGA): Is it an astrocytoma? Morphological, immunohistochemical and ultrastructural study. Neuropathology 2009, 29:25-30

3. Kim SK, Wang KC, Cho BK, Jung HW, Lee YJ, Chung YS, Lee JY Park SH, Kim YM, Choe G, Chi JG: Biological behavior and tumorigenesis of subependymal giant cell astrocytomas. J Neurooncol 2001, 52:217-225

4. Jozwiak S, Schwartz RA, Janniger CK, Bielicka-Cymerman J: Usefulness of diagnostic criteria of tuberous sclerosis complex in pediatric patients. J Child Neurol 2000, 15:652-659

5. Jozwiak S, Goodman M, Lamm SH: Poor mental development in patients with tuberous sclerosis complex: clinical risk factors. Arch Neurol 1998, 55:379-384

6. European Chromosome 16 Tuberous Sclerosis Consortium: Identification and characterization of the tuberous sclerosis gene on chromosome 16. Cell 1993, 75:1305-1315

7. van Slegtenhorst M, de Hoogt R, Hermans C, Nellist M, Janssen B Verhoef S, Lindhout D, van den Ouweland A, Halley D, Young J, Burley M, Jeremiah S, Woodward K, Nahmias J, Fox M, Ekong R, Osborne J, Wolfe J, Povey S, Snell RG, Cheadle JP, Jones AC, Tachataki M, Ravine D, Sampson JR, Reeve MP, Richardson P, Wilmer F, Munro C, Hawkins TL, Sepp T, Ali JB, Ward S, Green AJ, Yates JR, Kwiatkowska J, Henske EP, Short MP, Haines JH, Jozwiak S, Kwiatkowski DJ: Identification of the tuberous sclerosis gene TSC1 on chromosome 9q34. Science 1997, 277:805-808

8. Benvenuto G, Li S, Brown SJ, Braverman R, Vass WC, Cheadle JP, Halley DJ, Sampson JR, Wienecke R, DeClue JE: The tuberous sclerosis-1 (TSC1) gene product hamartin suppresses cell growth and augments the expression of the TSC2 product tuberin by inhibiting its ubiquitination. Oncogene 2000, 19:6306-6316

9. Chong-Kopera H, Inoki K, Li Y, Zhu T, Garcia-Gonzalo FR, Rosa JL, Guan KL: TSC1 stabilizes TSC2 by inhibiting the interaction between TSC2 and the HERC1 ubiquitin ligase. J Biol Chem 2006, 281: 8313-8316

10. Zhang Y, Gao X, Saucedo LJ, Ru B, Edgar BA, Pan D: Rheb is a direct target of the tuberous sclerosis tumour suppressor proteins. Nat Cell Biol 2003, 5:578-581

11. Burnett PE, Barrow RK, Cohen NA, Snyder SH, Sabatini DM: RAFT1 phosphorylation of the translational regulators p70 S6 kinase and 4E-BP1. Proc Natl Acad Sci USA 1998, 95:1432-1437

12. Fingar DC, Blenis J: Target of rapamycin (TOR): an integrator of nutrient and growth factor signals and coordinator of cell growth and cell cycle progression. Oncogene 2004, 23:3151-3171

13. Wullschleger $S$, Loewith $R$, Hall MN: TOR signaling in growth and metabolism. Cell 2006, 124:471-484

14. Franz DN, Leonard J, Tudor C, Chuck G, Care M, Sethuraman G, Dinopoulos A, Thomas G, Crone KR: Rapamycin causes regression 
of astrocytomas in tuberous sclerosis complex. Ann Neurol 2006 59:490-498

15. Sampson JR: Therapeutic targeting of mTOR in tuberous sclerosis. Biochem Soc Trans 2009, 37:259-264

16. Hardwick JS, Kuruvilla FG, Tong JK, Shamji AF, Schreiber SL: Rapamycin-modulated transcription defines the subset of nutrient-sensitive signaling pathways directly controlled by the Tor proteins. Proc Natl Acad Sci USA 1999, 96:14866-14870

17. Chan TF, Carvalho J, Riles L, Zheng XF: A chemical genomics approach toward understanding the global functions of the target of rapamycin protein (TOR). Proc Natl Acad Sci USA 2000, 97: 13227-13232

18. Xie MW, Jin F, Hwang H, Hwang S, Anand V, Duncan MC, Huang J: Insights into TOR function and rapamycin response: chemical genomic profiling by using a high-density cell array method. Proc Natl Acad Sci USA 2005, 102:7215-7220

19. Guertin DA, Guntur KV, Bell GW, Thoreen CC, Sabatini DM: Functional genomics identifies TOR-regulated genes that control growth and division. Curr Biol 2006, 16:958-970

20. Onda H, Crino PB, Zhang H, Murphey RD, Rastelli L, Gould Rothberg BE, Kwiatkowski DJ: Tsc2 null murine neuroepithelial cells are a model for human tuber giant cells, and show activation of an mTOR pathway. Mol Cell Neurosci 2002, 21:561-574

21. Irizarry RA, Bolstad BM, Collin F, Cope LM, Hobbs B, Speed TP: Summaries of Affymetrix GeneChip probe level data. Nucleic Acids Res 2003, 31:e15

22. Wu Z, Irizarry RA: Preprocessing of oligonucleotide array data. Nature Biotechnol 2004, 22:656-658; author reply 658

23. Li C, Hung Wong W: Model-based analysis of oligonucleotide arrays: model validation, design issues and standard error application. Genome Biol 2001, 2:RESEARCH0032

24. Zhang L, Miles MF, Aldape KD: A model of molecular interactions on short oligonucleotide microarrays. Nature Biotechnol 2003, 21 : $818-821$

25. Gentleman RC, Carey VJ, Bates DM, Bolstad B, Dettling M, Dudoit S, Ellis B, Gautier L, Ge Y, Gentry J, Hornik K, Hothorn T, Huber W, lacus S, Irizarry R, Leisch F, Li C, Maechler M, Rossini AJ, Sawitzki G, Smith C, Smyth G, Tierney L, Yang JY, Zhang J: Bioconductor: open software development for computational biology and bioinformatics. Genome Biol 2004, 5:R80

26. Ciechomska I, Pyrzynska B, Kazmierczak P, Kaminska B: Inhibition of Akt kinase signalling and activation of Forkhead are indispensable for upregulation of FasL expression in apoptosis of glioma cells. Oncogene 2003, 22:7617-7627

27. Jozwiak J, Grajkowska W, Kotulska K, Jozwiak S, Zalewski W, Zajaczkowska A, Roszkowski M, Slupianek A, Wlodarski P: Brain tumor formation in tuberous sclerosis depends on Erk activation. Neuromolecular Med 2007, 9:117-127

28. Jozwiak J, Jozwiak S, Wlodarski P: Possible mechanisms of disease development in tuberous sclerosis. Lancet Oncol 2008, 9:73-79

29. Govindarajan B, Mizesko MC, Miller MS, Onda H, Nunnelley M, Casper K, Brat D, Cohen C, Arbiser JL: Tuberous sclerosis-associated neoplasms express activated p42/44 mitogen-activated protein (MAP) kinase, and inhibition of MAP kinase signaling results in decreased in vivo tumor growth. Clin Cancer Res 2003, 9:3469-3475

30. Klemke RL, Cai S, Giannini AL, Gallagher PJ, de Lanerolle P, Cheresh DA: Regulation of cell motility by mitogen-activated protein kinase. J Cell Biol 1997, 137:481-492

31. Pullikuth AK, Catling AD: Scaffold mediated regulation of MAPK signaling and cytoskeletal dynamics: a perspective. Cell Signal 2007 19:1621-1632

32. Ruano Y, Mollejo M, Camacho FI, Rodriguez de Lope A, Fiano C Ribalta T, Martinez P. Hernandez-Moneo JL, Melendez B: Identification of survival-related genes of the phosphatidylinositol $3^{\prime}$ kinase signaling pathway in glioblastoma multiforme. Cancer 2008, 112:1575-1584

33. Bai XF, Ni XG, Zhao P, Liu SM, Wang HX, Guo B, Zhou LP, Liu F, Zhang JS, Wang K, Xie YQ, Shao YF, Zhao XH: Overexpression of annexin 1 in pancreatic cancer and its clinical significance. World $J$ Gastroenterol 2004, 10:1466-1470

34. Garcia Pedrero JM, Fernandez MP, Morgan RO, Herrero Zapatero A, Gonzalez MV, Suarez Nieto C, Rodrigo JP: Annexin A1 down-regulation in head and neck cancer is associated with epithelial differentiation status. Am J Pathol 2004, 164:73-79
35. Shen D, Chang HR, Chen Z, He J, Lonsberry V, Elshimali Y, Chia D, Seligson D, Goodglick L, Nelson SF, Gornbein JA: Loss of annexin A1 expression in human breast cancer detected by multiple high-throughput analyses. Biochem Biophys Res Commun 2005, 326:218-227

36. Mailliard WS, Haigler HT, Schlaepfer DD: Calcium-dependent binding of S100C to the N-terminal domain of annexin I. J Biol Chem 1996, 271:719-725

37. Memon AA, Sorensen BS, Meldgaard P, Fokdal L, Thykjaer T, Nexo E: Down-regulation of $\mathrm{S} 100 \mathrm{C}$ is associated with bladder cancer progression and poor survival. Clin Cancer Res 2005, 11:606-611

38. Kondo A, Sakaguchi M, Makino E, Namba M, Okada S, Huh NH: Localization of $\mathrm{S} 100 \mathrm{C}$ immunoreactivity in various human tissues. Acta Med Okayama 2002, 56:31-34

39. Cross SS, Hamdy FC, Deloulme JC, Rehman I: Expression of S100 proteins in normal human tissues and common cancers using tissue microarrays: S100A6. S100A8, S100A9 and S100A11 are all overexpressed in common cancers. Histopathology 2005, 46:256-269

40. Rehman I, Azzouzi AR, Cross SS, Deloulme JC, Catto JW, Wylde N, Larre S, Champigneuille J, Hamdy FC: Dysregulated expression of S100A11 (calgizzarin) in prostate cancer and precursor lesions. Hum Pathol 2004, 35:1385-1391

41. Sakaguchi M, Miyazaki M, Inoue $Y$, Tsuji T, Kouchi H, Tanaka T, Yamada H, Namba M: Relationship between contact inhibition and intranuclear S100C of normal human fibroblasts. J Cell Biol 2000, 149:1193-1206

42. Kuan CT, Wakiya K, Dowell JM, Herndon JE, 2nd, Reardon DA, Graner MW, Riggins GJ, Wikstrand CJ, Bigner DD: Glycoprotein nonmetastatic melanoma protein B, a potential molecular therapeutic target in patients with glioblastoma multiforme. Clin Cancer Res 2006, 12:1970-1982

43. Rose AA, Pepin F, Russo C, Abou Khalil JE, Hallett M, Siegel PM: Osteoactivin promotes breast cancer metastasis to bone. Mol Cancer Res 2007, 5:1001-1014

44. Weterman MA, Ajubi N, van Dinter IM, Degen WG, van Muijen GN, Ruitter DJ, Bloemers HP: nmb, a novel gene, is expressed in lowmetastatic human melanoma cell lines and xenografts. Int $\mathrm{J}$ Cancer 1995, 60:73-81

45. He J, Furmanski P: Sequence specificity and transcriptional activation in the binding of lactoferrin to DNA. Nature 1995, 373:721-724

46. Bozinov O, Kohler S, Samans B, Benes L, Miller D, Ritter M, Sure U, Bertalanffy $\mathrm{H}$ : Candidate genes for the progression of malignant gliomas identified by microarray analysis. Neurosurg Rev 2008, 31: 83-89; discussion 89-90

47. Zhou Y, Zeng Z, Zhang W, Xiong W, Wu M, Tan Y, Yi W, Xiao L, Li X, Huang C, Cao L, Tang K, Shen S, Li G: Lactotransferrin: a candidate tumor suppressor-Deficient expression in human nasopharyngeal carcinoma and inhibition of NPC cell proliferation by modulating the mitogen-activated protein kinase pathway. Int J Cancer 2008, 123: 2065-2072

48. Ridley AJ: Rho proteins and cancer. Breast Cancer Res Treat 2004, 84:13-19

49. Poch E, Minambres R, Mocholi E, Ivorra C, Perez-Arago A, Guerri C, Perez-Roger I, Guasch RM: RhoE interferes with Rb inactivation and regulates the proliferation and survival of the U87 human glioblastoma cell line. Exp Cell Res 2007, 313:719-731

50. Bektic J, Pfeil K, Berger AP, Ramoner R, Pelzer A, Schafer G, Kofler K, Bartsch G, Klocker H: Small G-protein RhoE is underexpressed in prostate cancer and induces cell cycle arrest and apoptosis. Prostate $2005,64: 332-340$

51. Carmon KS, Loose DS: Secreted frizzled-related protein 4 regulates two Wnt7a signaling pathways and inhibits proliferation in endometrial cancer cells. Mol Cancer Res 2008, 6:1017-1028

52. Liu TH, Raval A, Chen SS, Matkovic JJ, Byrd JC, Plass C: CpG island methylation and expression of the secreted frizzled-related protein gene family in chronic Iymphocytic leukemia. Cancer Res 2006, 66:653-658

53. Brockschnieder D, Sabanay H, Riethmacher D, Peles E: Ermin, a myelinating oligodendrocyte-specific protein that regulates cell morphology. J Neurosci 2006, 26:757-762

54. Kirkpatrick LL, Matzuk MM, Dodds DC, Perin MS: Biochemical interactions of the neuronal pentraxins. Neuronal pentraxin (NP) receptor binds to taipoxin and taipoxin-associated calcium-binding protein 49 via NP1 and NP2. J Biol Chem 2000, 275:17786-17792

55. Sia GM, Beique JC, Rumbaugh G, Cho R, Worley PF, Huganir RL: 
Interaction of the N-terminal domain of the AMPA receptor GluR4 subunit with the neuronal pentraxin NP1 mediates GluR4 synaptic recruitment. Neuron 2007, 55:87-102

56. Munoz EM, Bailey MJ, Rath MF, Shi Q, Morin F, Coon SL, Moller M, Klein DC: NeuroD1: developmental expression and regulated genes in the rodent pineal gland. J Neurochem 2007, 102:887-899

57. Lamolet B, Poulin G, Chu K, Guillemot F, Tsai MJ, Drouin J: Tpitindependent function of NeuroD1(BETA2) in pituitary corticotroph differentiation. Mol Endocrinol 2004, 18:995-1003

58. Sharma A, Moore M, Marcora E, Lee JE, Qiu Y, Samaras S, Stein R: The NeuroD1/BETA2 sequences essential for insulin gene transcription colocalize with those necessary for neurogenesis and p300/ CREB binding protein binding. Mol Cell Biol 1999, 19:704-713
59. Kamath SG, Chen N, Enkemann SA, Sanchez-Ramos J: Transcriptional profile of NeuroD expression in a human fetal astroglial cell line. Gene Expr 2005, 12:123-136

60. Liu M, Pleasure SJ, Collins AE, Noebels JL, Naya FJ, Tsai MJ, Lowenstein DH: Loss of BETA2/NeuroD leads to malformation of the dentate gyrus and epilepsy. Proc Natl Acad Sci USA 2000, 97: 865-870

61. Cohen M, Hartlage PL, Krawiecki N, Roesel RA, Carter AL, Hommes FA: Serum carnosinase deficiency: a non-disabling phenotype? J Ment Defic Res 1985, 29 (Pt 4):383-389

62. Lunde HA, Gjessing LR, Sjaastad O: Homocarnosinosis: influence of dietary restriction of histidine. Neurochem Res 1986, 11 : 825-838 